\title{
Protocol
}

\section{Cultures of Cerebellar Granule Neurons}

\author{
Parizad M. Bilimoria and Azad Bonni ${ }^{1}$ \\ Department of Pathology and Program in Neuroscience, Harvard Medical School, Boston, MA 02115, USA
}

\section{INTRODUCTION}

Primary cultures of granule neurons from the post-natal rat cerebellum provide an excellent model system for molecular and cell biological studies of neuronal development and function. The cerebellar cortex, with its highly organized structure and few neuronal subtypes, offers a well-characterized neural circuitry. Many fundamental insights into the processes of neuronal apoptosis, migration, and differentiation in the mammalian central nervous system have come from investigating granule neurons in vitro. Granule neurons are the most abundant type of neurons in the brain. In addition to the sheer volume of granule neurons, the homogeneity of the population and the fact that they can be transfected with ease render them ideal for elucidating the molecular basis of neuronal development. This protocol for isolating granule neurons from post-natal rats is relatively straightforward and quick, making use of standard enzymatic and mechanical dissociation methods. In a serum-based medium containing an inhibitor of mitosis, cerebellar granule neurons can be maintained with high purity. Axons and dendrites can be clearly distinguished on the basis of morphology and markers. For even greater versatility, this protocol for culturing granule neurons can be combined with knockout or transgenic technologies, or used in cerebellar slice overlay assays.

\section{RELATED INFORMATION}

This protocol was adapted from methods originally developed in the work of Messer (1977), Gallo et al. (1982), Thangnipon et al. (1983), D’Mello et al. (1993) and Dudek et al. (1997).

\section{MATERIALS}

CAUTIONS AND RECIPES: Please see Appendices for appropriate handling of materials marked with $<!>$, and recipes for reagents marked with $<\mathbf{R}>$.

\section{Reagents}

$<$ R $><$ ! $>$ AraC (Cytosine-1- $\beta$-D-arabinofuranoside) solution

Basal Medium Eagle (BME)

$<\mathrm{R}>$ Culture medium for granule neurons

$<$ R $>$ DNase $(2 \mathrm{mg} / \mathrm{mL})(0.5-\mathrm{mL}$ aliquot for trituration; see Step 10)

Glucose (1 M)

$<$ R $>$ HHGN dissection solution

$<\mathrm{R}>$ Poly-L-ornithine-coated plates (of desired size, depending on experiments to be performed; see Step 15) 
Rats, Long-Evans (post-natal day 6 [P6]) (one litter)

$<$ ! $>$ Trypan blue

$<\mathbf{R}><$ ! $>$ Trypsin-DNase solution

\section{Equipment}

Centrifuge

$<$ ! $>\mathrm{CO}_{2}$ chamber

Forceps, fine (Dumont \#5)

A second pair of forceps of any variety is also required.

Hemacytometer

Hood, laminar flow

Ice bucket and ice

Incubator preset to $37^{\circ} \mathrm{C}\left(5 \% \mathrm{CO}_{2}\right)$

Micropipettor with tips

Microscope, dissection

Pipettes (5-mL)

Scissors, surgical (large and small)

Timer for timing incubations

Tubes (Falcon, 50-mL)

Water bath preset to $37^{\circ} \mathrm{C}$

\section{METHOD}

\section{Isolation of Cerebella}

1. Prepare poly-L-ornithine-coated plates and solutions.

2. Euthanize P6 Long-Evans rats using a $\mathrm{CO}_{2}$ chamber.

To prevent having more than a few minutes lag time between the euthanasia and removal of the cerebella, consider doing this step in two parts.

3. Decapitate pups. To isolate the cerebella, begin by grasping a pup head at the nose and insert small surgical scissors into the foramen magnum (the aperture at the base of the skull through which the medulla and spinal cord extend). Proceed laterally, then anteriorly through the ear, and curve toward the midline. After reaching the midline from one side, reinsert scissors into the foramen magnum, and repeat the cutting procedure on the other side.

The two incisions should meet at the midline.

4. Using forceps, carefully lift the skull upward, and flip it back until the hindbrain is exposed (Fig. 1A). Make sure that, as the skull is lifted, the brain remains in the base of the skull.

5. If necessary, cut away any bone or other tissues that are obstructing the sides of the cerebellum. Extract the cerebellum with forceps (Fig. 1B), and place it into a dish containing at least $5 \mathrm{~mL}$ of HHGN dissection solution.

See Troubleshooting.

6. After isolation of the cerebella, use the dissection scope and fine forceps to remove the meninges, as well as any large blood vessels or extraneous brain regions that are stuck to the cerebella.

This step should be performed at a steady pace, with a plate of ice underneath the plate of cerebella. The meninges tend to come off most easily if you start by pulling away residual choroid plexus from the ventral side, where the fourth ventricle was located.

\section{Dissociation and Culture of Cells}

If you are working with two litters, an additional step of trituration is helpful; see Step 11.iv. 

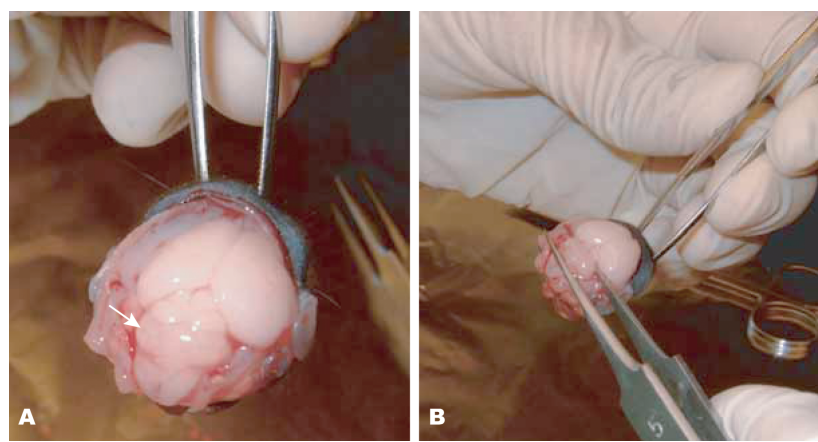

FIGURE 1. Dissection of rat cerebellum. (A) Posterior view of the brain of a post-natal day 6 rat pup. (From top to bottom) The regions exposed are the cerebral hemispheres, midbrain, cerebellum, and superior portion of the medulla. (Arrow) Cerebellum. (B) Positioning of forceps for removal of cerebellum.

7. Working in the tissue culture hood, decant the dish of cerebella into a 50-mL Falcon tube. Use a pipette to remove most of the HHGN solution, and then add at least $5 \mathrm{~mL}$ of fresh HHGN solution. Repeat this for a total of three washes.

8. After removing the last $\mathrm{HHGN}$ wash, add $5 \mathrm{~mL}$ of trypsin-DNase solution, being sure to first mix the solution by pipetting up and down. Place the tube in a $37^{\circ} \mathrm{C}$ water bath for $10 \mathrm{~min}$. Gently swirl the cerebella every 5 min.

9. Wash three times with HHGN solution as in Step 7.

10. Prepare an aliquot of DNase for trituration by adding $250 \mu \mathrm{L}$ of DNase to $5 \mathrm{~mL}$ of BME in a separate Falcon tube. Mix by pipetting.

If you are working with two litters, you will need $\sim 2 \mathrm{~mL}$ more of the DNase solution for additional trituration (Step 11.iv).

11. Remove the last HHGN wash, and add the diluted DNase solution from Step 10 to the cerebella. Dissociate by pipetting up and down with a $5-\mathrm{mL}$ pipette as follows:

Avoiding bubbles is critical at this step.

i. For approximately the first 15 rounds of pipetting, do not press the pipette tip against the very bottom of the tube; rather, allow the cerebella to fall apart into smaller chunks.

See Troubleshooting.

ii. Continue to pipette up and down, but begin gently pressing the pipette tip against the bottom of the tube.

After approximately 10 more rounds of pipetting, you will find that the pieces of tissue are not becoming any smaller.

iii. Press the pipette tip more firmly against the bottom of the tube, and continue the trituration until clumps of tissue are no longer visible.

iv. To perform an additional trituration, transfer the cell suspension to ice for $5 \mathrm{~min}$, allowing any remaining undetected clumps to sink to the bottom. Transfer the top half of the cell solution to a separate Falcon tube, and triturate the bottom again using fresh DNase solution.

12. Centrifuge cells at $\sim 200 \mathrm{~g}$ for $5 \mathrm{~min}$ at $4^{\circ} \mathrm{C}$.

See Troubleshooting.

13. Use a pipette to remove the supernatant. Add $5 \mathrm{~mL}$ of culture medium for granule neurons, and pipette up and down until a homogeneous mixture is obtained. Add $10 \mathrm{~mL}$ more of culture medium incrementally, pipetting up and down after dispensing every $2-3 \mathrm{~mL}$ to ensure that the mixture remains homogeneous.

14. Place the cell suspension on ice, and count a small aliquot using a hemacytometer: 
i. Make a 1:10 dilution of cells by adding $100 \mu \mathrm{L}$ of the cell suspension to $650 \mu \mathrm{L}$ of culture medium and $250 \mu \mathrm{L}$ of trypan blue.

ii. Count healthy, spherical cells with a halo. Do not count cells that take up the trypan blue. The expected yield is 10-15 million cells per cerebellum.

See Troubleshooting.

15. Plate cells at the desired density. For morphological assays in 24-well plates with coverslips, use 1720 million cells per plate. For biochemical experiments in six-well plates, use 30 million cells per plate. Scale up for larger plates.

16. Maintain cells by adding AraC solution $\sim 24 \mathrm{~h}$ after plating cells to a final concentration of $10 \mu \mathrm{M}$. On day in vitro 3 (DIV3), add $1 \mathrm{M}$ glucose to a final concentration of $25 \mathrm{mM}$.

See Troubleshooting.

\section{TROUBLESHOOTING}

Problem: Cerebella are broken upon removal.

[Step 5]

Solution: Consider the following:

1. To make sure that your incisions are not too deep, cut incrementally, removing the scissors and reinserting them after each small incision.

2. Pull away from the center as you cut, such that you are making an incision in the skull without damaging any of the soft tissue inside.

3. Do not extract the cerebellum until it is fully exposed, making sure you have cut away any obstructing tissue on the sides.

Problem: Cerebella do not fall apart easily after trypsinization.

[Step 11.i]

Solution: Trypsinize longer, for 15-20 min. If this does not help, make fresh trypsin-DNase aliquots, checking that the concentrations are accurate. When the trypsinization has worked properly, the cerebella should appear softened.

Problem: A viscous pellet is observed after centrifugation.

[Step 12]

Solution: The DNase may be spoiled or not concentrated enough. Add $50 \mu \mathrm{L}$ more of the 2-mg/mL aliquot, and further dissociate the cells.

Problem: Cells clumps are visible during counting.

[Step 14]

Solution: Apply more pressure when triturating, and observe the solution carefully for any residual clumps before centrifuging cells.

Problem: There is a low yield of healthy cells and a high rate of cell death.

[Steps 14 and 16]

Solution: There are many causes for this problem. Consider the following:

1. Most likely, the trypsinization or trituration was too harsh. Add trypsin for a shorter amount of time, and apply less pressure when dissociating the cells.

2. Make sure the culture preparation does not exceed $2 \mathrm{~h}$.

3. If problems persist, prepare all the solutions and the ethanol-rinsed coverslips again.

4. A change in serum lot can have an adverse impact on the health of cultures.

Problem: Cells clump together after a few days in culture.

[Step 16]

Solution: Plating density is probably lower than expected from the count. Be sure not to count the unhealthy cells, which take up trypan blue. 
Problem: Cells are not attached, or there are regions of the plate with no cells.

[Step 16]

Solution: Consider the following:

1. The coating may not have been even. Make sure the poly-L-ornithine solution covers the entire well, and, if using coverslips, ensure that they do not float up. (Press down with a pipette tip if they float.)

2. Make sure to wash the plates thoroughly with $\mathrm{H}_{2} \mathrm{O}$.

Problem: There are too many glia.

[Step 16]

Solution: Consider the following:

1. Remove meninges at a steady pace so that the time between cerebella extraction and trypsin treatment does not exceed $30 \mathrm{~min}$.

2. Be certain pups are of the right age.

3. If the above factors are not the cause of the problem, prepare fresh AraC solution.

4. If glia levels remain high, increase AraC concentration to $15 \mu \mathrm{M}$. If you are keeping the cells in culture for longer than 4-5 d, add a second dose of AraC on DIV3.

\section{DISCUSSION}

Cerebellar granule neurons have proven invaluable in uncovering the signaling pathways governing neuronal survival, migration, and differentiation. Studies of neuronal apoptosis have frequently relied on cultures of granule neurons, exploiting their responses to activity and growth factor deprivation as well as oxidative stress. These studies have led to the identification of key neuroprotective molecules including insulin-like growth factor 1, cyclic adenosine monophosphate, phosphatidylinositol-3 kinase, AKT, and myocyte enhancer factor 2 (D'Mello et al. 1993, 1997; Dudek et al. 1997; Mao et al. 1999; Li et al. 2001; Shalizi et al. 2003) and key mediators of neuronal cell death including cyclindependent kinase 1, c-Jun N-terminal kinase, and mammalian sterile 20-like kinase (Watson et al. 1998; Harris and Johnson 2001; Konishi et al. 2002; Becker and Bonni 2006; Lehtinen et al. 2006; for review, see Becker and Bonni 2004).

The classic paradigm for studying activity-dependent responses in granule neurons has been the use of membrane-depolarizing concentrations of extracellular potassium chloride (Gallo et al. 1987; Yan et al. 1994). Membrane depolarization activates voltage-sensitive calcium channels, leading to the entry of calcium into neurons and the activation of calcium-dependent signaling molecules, including $\mathrm{Ca}^{2+}$-calmodulin-dependent protein kinases and the phosphatase calcineurin (Sée et al. 2001; Linseman et al. 2003; Wayman et al. 2004; Sato et al. 2005; Suzuki et al. 2005). Calcium-dependent signaling pathways regulate the gene expression profile of cerebellar granule neurons (Kramer et al. 2003; Sato et al. 2005). An interesting example is the developmental switch that occurs in subunit composition for $\mathrm{GABA}_{\mathrm{A}}$ and NMDA neurotransmitter receptors as granule neurons mature (Watanabe et al. 1992; Farrant et al. 1994; Mathews et al. 1994). Upon hyperpolarization, the $\alpha 6$ subunits of the $\mathrm{GABA}_{A}$ receptor and the NR2C subunit of the NMDA receptor are up-regulated (Mellor et al. 1998; Suzuki et al. 2005; for review, see Nakanishi and Okazawa 2006).

Another realm in which granule neurons have occupied center stage is the study of neuronal migration. Granule neurons display a well-known maturation-dependent descent from the external to internal granular layer of the cerebellar cortex. They have been particularly useful in uncovering glial guidance mechanisms for neuronal migration, shedding light on both the cell biology of the migration process and the specific molecular pathways involved. Two crucial regulators of neuronal migration that were identified in studies of cerebellar granule neurons are the adhesion molecule astrotactin and members of the mPar6 $\alpha$ polarity complex (Rivas and Hatten 1995; Zheng et al. 1996; Solecki et al. 2004; for review, see Stitt et al. 1991; Solecki et al. 2006).

Most recently, granule neurons have been used to study the cell-intrinsic mechanisms underlying neuronal morphogenesis and connectivity. The transcription factors MEF2 and NeuroD, as well as the ubiquitin ligase Cdh1-APC and its target SnoN, have been identified as key regulators of morphological development in neurons (Gaudillière et al. 2004; Konishi et al. 2004; Shalizi et al. 2006; Stegmüller 
et al. 2006). For these studies, granule neurons offer the benefit of having a highly stereotypical pattern of polarization with readily distinguishable axons and dendrites. In terms of understanding neuronal connectivity on a broader scale, perhaps the best asset of granule neurons is the relatively simple architecture of the cerebellar cortex, as this may facilitate translating molecular findings about individual cell types into functional consequences for a circuit.

In contrast to the ease of culturing granule neurons, Purkinje neurons-the post-synaptic targets of granule neurons-are notoriously challenging to isolate and maintain in culture. Although recent improvements in culture techniques may increase the survival and differentiation of Purkinje neurons in mixed cerebellar cultures (Furuya et al. 1998; Ito-Ishida et al. 2008), the overall number of Purkinje neurons in such cultures remains quite low. Purifying Purkinje neurons can require Percoll sedimentation and immunopanning technologies (Baptista et al. 1994), which are more expensive and laborintensive than most neuronal culture protocols. In addition to this difficulty of culturing post-synaptic targets, cerebellar granule neurons develop post-natally, making it difficult to study granule neurons from the many knockout mice that die embryonically or at birth. However, the post-natal development of granule neurons can also be advantageous because the post-natal cerebellum is much easier to isolate than small regions of the embryonic cerebrum.

\section{ACKNOWLEDGMENTS}

We apologize to all investigators whose important studies of cerebellar granule neurons could not be cited due to space limitations. We thank members of the Bonni laboratory for refining these culture methods and providing critical readings of the manuscript. Work in the Bonni laboratory is supported by grants from the National Institutes of Health.

\section{REFERENCES}

Baptista, C.A., Hatten, M.E., Blazeski, R., and Mason, C.A. 1994. Cellcell interactions influence survival and differentiation of purified Purkinje cells in vitro. Neuron 12: 243-260.

Becker, E.B. and Bonni, A. 2004. Cell cycle regulation of neuronal apoptosis in development and disease. Prog. Neurobiol. 72: 1-25.

Becker, E.B. and Bonni, A. 2006. Pin1 mediates neural-specific activation of the mitochondrial apoptotic machinery. Neuron 49: 655662.

D'Mello, S.R., Galli, C., Ciotti, T., and Calissano, P. 1993. Induction of apoptosis in cerebellar granule neurons by low potassium: Inhibition of death by insulin-like growth factor 1 and cAMP. Proc. Natl. Acad. Sci. 90: 10989-10993.

D'Mello, S.R., Borodezt, K., and Soltoff, S.P. 1997. Insulin-like growth factor and potassium depolarization maintain neuronal survival by distinct pathways: Possible involvement of PI 3-kinase in IGF-1 signaling. J. Neurosci. 17: 1548-1560.

Dudek, H., Datta, S.R., Franke, T.F., Birnbaum, M.J., Yao, R., Cooper, G.M., Segal, R.A., Kaplan, D.R., and Greenberg, M.E. 1997. Regulation of neuronal survival by the serine-threonine protein kinase AKT. Science 275: 661-665.

Farrant, M., Feldmeyer, D., Takahashi, T., and Cull-Candy, S.G. 1994. NMDA-receptor channel diversity in the developing cerebellum. Nature 368: 335-339.

Furuya, S., Makino, A., and Hirabayashi, Y. 1998. An improved method for culturing cerebellar Purkinje cells with differentiated dendrites under a mixed monolayer setting. Brain Res. Brain Res. Protoc. 3: 192-198.

Gallo, V., Ciotti, M.T., Coletti A, Aloisi, F., and Levi, G. 1982. Selective release of glutamate from cerebellar granule cells differentiating in culture. Proc. Natl. Acad. Sci. 79: 7919-7923.

Gallo, V., Kingsbury, A., Balázs, R., and Jørgensen, O.S. 1987. The role of depolarization in the survival and differentiation of cerebellar granule cells in culture. J. Neurosci. 7: 2203-2213.

Gaudillière, B., Konishi, Y., de la Iglesia, N., Yao, G., and Bonni, A. 2004. A CaMKII-NeuroD signaling pathway specifies dendritic morphogenesis. Neuron 41: 229-241.

Harris, C.A. and Johnson Jr., E.M. 2001. BH3-only Bcl-2 family mem- bers are coordinately regulated by the JNK pathway and require Bax to induce apoptosis in neurons. J. Biol. Chem. 276: 3775437760.

Ito-Ishida, A., Miura, E., Emi, K., Matsuda, K., lijima, T., Kondo, T., Kohda, K., Watanabe, M., and Yuzaki, M. 2008. Cbln1 regulates rapid formation and maintenance of excitatory synapses in mature cerebellar Purkinje cells in vitro and in vivo. J. Neurosci. 28: 5920-5930.

Konishi, Y., Lehtinen, M., Donovan, N., and Bonni, A. 2002. Cdc2 phosphorylation of BAD links the cell cycle to the cell death machinery. Mol. Cell 9: 1005-1016.

Konishi, Y., Stegmüller, J., Matsuda, T., Bonni, S., and Bonni, A. 2004. Cdh1-APC controls axonal growth and patterning in the mammalian brain. Science 303: 1026-1030.

Kramer, D., Fresu, L., Ashby, D.S., Freeman, T.C., and Genazzani, A.A. 2003. Calcineurin controls the expression of numerous genes in cerebellar granule cells. Mol. Cell. Neurosci. 23: 325-330.

Lehtinen, M., Yuan, Z., Boag, P., Yang, Y., Villen, J., Becker, E., DiBacco, S., de la Iglesia, N., Gygi, S., Blackwell, T.K., et al. 2006. A conserved MST-FOXO signaling pathway mediates oxidative stress responses and extends lifespan. Cell 125: 987-1001.

Li, M., Linseman, D.A., Allen, M.P., Meintzer, M.K., Wang, X., Laessig, T., Wierman, M.E., and Heidenreich, K.A. 2001. Myocyte enhance factor 2A and 2D undergo phosphorylation and caspase-mediated degradation during apoptosis of rat cerebellar granule neurons. J. Neurosci. 21: 6544-6552.

Linseman, D.A., Bartley, C.M., Le, S.S., Laessig, T.A., Bouchard, R.J., Meintzer, M.K., Li, M., and Heidenreich, K.A. 2003. Inactivation of the myocyte enhancer factor-2 repressor histone deacetylase5 by endogenous $\mathrm{Ca}^{(2+)} /$ calmodulin-dependent kinase II promotes depolarization-mediated cerebellar granule neuron survival. J. Biol. Chem. 278: 41472-41481.

Mao, Z., Bonni, A., Xia, F., Nadal-Vicens, M., and Greenberg, M.E. 1999. Neuronal activity-dependent cell survival mediated by transcription factor MEF2. Science 286: 785-790.

Mathews, G.C., Bolos-Sy, A.M., Holland, K.D., Isenberg, K.E., Covey, D.F., Ferrendelli, J.A., and Rothman, S.M. 1994. Developmental 
alteration in GABAA receptor structure and physiological properties in cultured cerebellar granule neurons. Neuron 13: 149-158.

Mellor, J.R., Merlo, D., Jones, A., Wisden, W., and Randall, A.D. 1998. Mouse cerebellar granule cell differentiation: Electrical activity regulates the GABAA receptor $\alpha 6$ subunit gene. J. Neurosci. 18: 2822-2833.

Messer, A. 1977. The maintenance and identification of mouse cerebellar granule cells in monolayer culture. Brain Res. 130: 1-12.

Nakanishi, S. and Okazawa, M. 2006. Membrane potential-regulated $\mathrm{Ca}^{2+}$ signalling in development and maturation of mammalian cerebellar granule cells. J. Physiol. 575: 389-395.

Rivas, R.J. and Hatten, M.E. 1995. Motility and cytoskeletal organization of migrating cerebellar granule neurons. J. Neurosci. 15: $981-$ 999.

Sato, M., Suzuki, K., Yamazaki, H., and Nakanishi, S. 2005. A pivotal role of calcineurin signaling in development and maturation of postnatal cerebellar granule cells. Proc. Natl. Acad. Sci. 102: 5874 5879.

Sée, V., Boutillier, A.L., Bito, H., and Loeffler, J.P. 2001. Calcium/calmodulin-dependent protein kinase type IV (CaMKIV) inhibits apoptosis induced by potassium deprivation in cerebellar granule neurons. FASEB J. 15: 134-144.

Shalizi, A., Lehtinen, M., Gaudillière, B., Donovan, N., Han, J., Konishi, Y., and Bonni, A. 2003. Characterization of a neurotrophin signaling mechanism that mediates neuronal survival in a temporally specific pattern. J. Neurosci. 23: 7326-7336.

Shalizi, A., Gaudillière, B., Yuan, Z., Shirogane, T., Stegmüller, J., Ge, Q., Tan, Y., Schulman, B., Harper, J.W., and Bonni, A. 2006. A calcium-regulated MEF2 sumoylation switch controls postsynaptic dendritic differentiation. Science 311: 1012-1017.

Solecki, D.J., Model, L., Gaetz, J., Kapoor, T.M., and Hatten, M.E. 2004. Par6 $\alpha$ signaling controls glial-guided neuronal migration. Nat. Neurosci. 7: 1195-1203.

Solecki, D.J., Govek, E.E., Tomoda, T., and Hatten, M.E. 2006.
Neuronal polarity in CNS development. Genes \& Dev. 20: 26392647.

Stegmüller, J., Konishi, Y., Huynh, M.A., Yuan, Z., DiBacco, S., and Bonni, A. 2006. Cell-intrinsic regulation of axonal morphogenesis by the Cdh1-APC target SnoN. Neuron 50: 389-400.

Stitt, T.N., Gasser, U.E., and Hatten, M.E. 1991. Molecular mechanisms of glial-guided neuronal migration. Ann. N.Y. Acad. Sci. 633: 113-121.

Suzuki, K., Sato, M., Morishima, Y., and Nakanishi, S. 2005. Neuronal depolarization controls brain-derived neurotrophic factorinduced upregulation of NR2C NMDA receptor via calcineurin signaling. J. Neurosci. 25: 9535-9543.

Thangnipon, W., Kingsbury, A., Webb, M., and Balazs, R. 1983. Observations on rat cerebellar cells in vitro: Influence of substratum, potassium concentration and relationship between neurons and astrocytes. Brain Res. 313: 177-189.

Watanabe, M., Inoue, Y., Sakimura, K., and Mishina, M. 1992. Developmental changes in distribution of NMDA receptor channel subunit mRNAs. Neuroreport 3: 1138-1140.

Watson, A., Eilers, A., Lallemand, D., Kyriakis, J., Rubin, L.L., and Ham, J. 1998. Phosphorylation of c-Jun is necessary for apoptosis induced by survival signal withdrawal in cerebellar granule neurons. J. Neurosci. 18: 751-762.

Wayman, G.A., Kaech, S., Grant, W.F., Davare, M., Impey, S., Tokumitsu, H., Nozaki, N., Banker, G., and Soderling, T.R. 2004. Regulation of axonal extension and growth cone motility by calmodulin-dependent protein kinase I. J. Neurosci. 24: 3786-3794.

Yan, G.M., Ni, B., Weller, M., Wood, K.A., and Paul, S.M. 1994 Depolarization or glutamate receptor activation blocks apoptotic cell death of cultured cerebellar granule neurons. Brain Res. 656 43-51.

Zheng, C., Heintz, N., and Hatten, M.E. 1996. CNS Gene encoding astrotactin, a gene which supports neuronal migration along glial fibers. Science 272: 417-419. 


\section{Cultures of Cerebellar Granule Neurons}

Parizad M. Bilimoria and Azad Bonni

Cold Spring Harb Protoc; doi: 10.1101/pdb.prot5107

\begin{tabular}{|c|c|}
\hline $\begin{array}{l}\text { Email Alerting } \\
\text { Service }\end{array}$ & Receive free email alerts when new articles cite this article - click here. \\
\hline $\begin{array}{l}\text { Subject } \\
\text { Categories }\end{array}$ & $\begin{array}{l}\text { Browse articles on similar topics from Cold Spring Harbor Protocols. } \\
\text { Cell Biology, general (1382 articles) } \\
\text { Cell Culture (301 articles) } \\
\text { Developmental Biology (728 articles) } \\
\text { Isolation ( } 34 \text { articles) } \\
\text { Laboratory Organisms, general (923 articles) } \\
\text { Neural Cell Culture (57 articles) } \\
\text { Neuroscience, general (357 articles) } \\
\text { Other Laboratory Organisms (68 articles) }\end{array}$ \\
\hline
\end{tabular}

